\title{
Representante de turma: Uma referência no desenvolvimento do protagonismo infantil e juvenil
}

\author{
Class representative: A reference in the development of child and youth protagonism
}

Recebido: 09/05/2021 | Revisado: 11/05/2021 | Aceito: 11/05/2021 | Publicado: 15/05/2021

\author{
Rosimar Alencar Silva Barbosa \\ ORCID: https://orcid.org/0000-0002-3974-5056 \\ Universidade Federal de Itajubá, Brasil \\ E-mail: pr_rosybarbosa@hotmail.com \\ Ricardo Shitsuka \\ ORCID: https://orcid.org/0000-0003-2630-1541 \\ Universidade Federal de Itajubá, Brasil \\ E-mail: rshitsuka@gmail.com \\ Karine Fortunato Silva Barbosa \\ ORCID: https://orcid.org/0000-0002-7583-7126 \\ Universidade Federal de Itajubá, Brasil \\ E-mail: karinefortunatob@gmail.com
}

\begin{abstract}
Resumo
O presente estudo foi desenvolvido na Escola Municipal Augusto de Carvalho, localizada no distrito de Resende/RJ é uma iniciativa do Serviço de Orientação Educacional/SOE. O objetivo do artigo é apresentar, discutir e refletir sobre ações que contribuem com a organização escolar por meio de lideranças comprometidas que sejam influenciadores positivos, a fim de promover o protagonismo infantil e juvenil. Entendendo que a sociedade contemporânea tem mudado drasticamente em todos os sentidos e requer cidadãos críticos-reflexivos e saiba conhecer, conviver, fazer e ser. Desenvolveu-se um trabalho de pesquisa-ação participativa voltado para a formação de novas lideranças. Pensando na relevância do assunto, e depois de analisar o contexto histórico da escola, verificou-se que desde a sua criação e inauguração, nunca houve eleição de representantes de turmas. Sendo um projeto pioneiro nessa unidade escolar e sabendo dos benefícios da parceria de crianças e jovens protagonistas, organizou-se junto aos professores a primeira eleição de representantes com alunos do $4^{\circ}$ e $5^{\circ}$ ano do Ensino Fundamental/ anos iniciais e $6^{\circ}$ e $7^{\circ}$ ano do Ensino Fundamental/anos finais. Percebeu-se que essa prática foi exitosa, por atrelar outras estratégias, entre elas, destaca-se o curso de formação continuada denominado, Liderança Comprometida, onde os novos líderes foram provocados a refletir sobre diversos temas pertinentes.
\end{abstract}

Palavras-chave: Protagonismo; Escola; Liderança; Ensino.

\begin{abstract}
The present study was developed at the Augusto de Carvalho Municipal School, located in the district of Resende / RJ, an initiative of the Educational Guidance Service / SOE, with the pedagogue Rosimar Alencar Silva as responsible. The purpose of the article is to present, discuss and reflect on actions that contribute to the school organization through committed leaders who are positive influencers, in order to promote child and youth leadership. Understanding that contemporary society has changed dramatically in every way and requires critical-reflective citizens and know how to know, live, do and be. A work of participatory action research was developed to train new leaders. Thinking about the relevance of the subject, and after analyzing the context of the Augusto de Carvalho school, it was found that in all its previous history there was no election of class representatives. So, knowing the benefits of having children and young protagonists as an ally, we organized, together with the teachers, the first election of representatives with students from the 4 th and 5th year of the initial years and the 6th and 7th year of the final years. This was an important milestone in the life of our school. After the elections, a continuous training course called, Committed Leadership, was offered, where students received mini lectures with the relevant topics
\end{abstract}

Keywords: Protagonism; School; Leadership; Teaching.

\section{Introdução}

A educação é tema importante em todas sociedades e épocas. Um exemplo, embora filosófico, vem de Rousseau como afiram Barbosa (2020) que considera a pedagogia proposta pelo genebrino que procura trabalhar a pessoa ou estudante em sua totalidade, isto é, além de preparar o indivíduo em sua subjetividade também orienta para a formação da cidadania. Considerando 
importante buscar um saber que pode ter acontecido em outros lugares e épocas, mas que leve os alunos à autonomia e desenvolvimento, procuramos desenvolver esse estudo.

A escola entre outras funções como é o caso de conservar a cultura local reacendendo essa cultura nos estudantes, trabalhar o saber geral da sociedade incentivando a leitura, o conhecimento da história, saberes, a aprendizagem da matemática e das ciências entre outras.

Fato importante é que a Lei Maior do Brasil conforme Brasil (1988) afirma no seu Artigo 20 que "A educação é um direito de todos, dever do Estado e da família, com a colaboração da sociedade civil, visando o pleno desenvolvimento da pessoa, seu preparo para o exercício da cidadania e sua qualificação para o trabalho". Em suma, a educação não é só para ser realizada pela escola e seus professores, mas é dever da família e da sociedade como um todo e sem a participação de todos não ocorre uma formação completa.

A Lei de Diretrizes e Bases da Educação/96 cita em seu artigo $1^{\circ}$ que: "A educação abrange os processos formativos que se desenvolvem na vida familiar, na convivência humana, no trabalho, nas instituições de ensino e pesquisa, nos movimentos sociais e organizações da sociedade civil e nos movimentos culturais”. Desta forma, verifica-se que a educação além tem uma relação, de alguma forma, com a formação de líderes.

A educação sob a perspectiva temporal é capaz de ultrapassar os limites do tempo escolar, indo além dos muros da escola. Assim a educação para a vida social articula vivências e saberes que preparam o cidadão com habilidades e competências socioemocionais para a vida em grupo e para os novos desafios da sociedade. Faria et al (2020) em um estudo voltado para o ensino de ciências na educação fundamental considera que as atividades práticas são importantes e quando elas são poucas na escola, uma das formas de aumentar é por meio de algum tipo de parceria com instituições de ensino superior. Apesar de ser do ensino de ciências há aspectos válidos em relação ao protagonismo das crianças na aprendizagem.

Outro estudo também voltado para o ensino fundamental foi realizado por Oliveira et al. (2020) e mostra que há decepção de professores quando os alunos da educação fundamental não alcançam os resultados esperados. Este aspecto nos faz refletir sobre a escolha dos temas a serem trabalhados bem como a necessidade de ter o protagonismo infantil e não o do adulto que está esperando outros resultados.

Num estudo realizado por Fernandes et al. (2019) no terceiro ano de uma escola de educação básica se observou que a escola em foco se mostrou como sendo uma grande incentivadora do aluno como um agente de mudanças.

Já no pressente estudo, o Serviço de Orientação Educacional de uma escola de educação básica observou que a clientela atendida era composta de excelentes alunos e com grande potencial, porém percebeu-se a necessidade de orientar e envolver esse público no cotidiano da escola, a fim de superar uma acentuada desmotivação de muitos, o que refletiu no baixo rendimento e na infrequência escolar.

O objetivo do artigo é apresentar, discutir e refletir sobre ações contextualizadas que contribuem com a organização escolar por meio de lideranças comprometidas que sejam influenciadores positivos, a fim de promover o protagonismo infantil e juvenil.

Olhar a escola sob uma nova perspectiva de dimensão formativa valorizando a criança como sujeito histórico de direitos e que se desenvolve por meio das interações, relações e práticas cotidianas. Entender que o aluno é a razão da escola existir e que o mesmo necessita ser ouvido e participar dos processos educativos, exercendo assim o seu protagonismo como ator social que é.

\section{Metodologia}

Pode-se definir a metodologia cientifica, como o estudo dos métodos de conhecer. O método científico é entendido como o conjunto de processos orientados por uma habilidade crítica e criadora voltada para a descoberta da verdade e para a 
construção da ciência hoje, a pesquisa constitui seu principal instrumento ou meio de acesso (Cervo \& Bervian, 2002). Para Lakatos e Marconi (1991), o método caracteriza-se como uma abordagem ampla, em nível de abstração elevado dos fenômenos da natureza e da sociedade. Para tanto, método se define como um modo de proceder seja um fazer, um agir, um conhecer, para alcançar um fim previamente projetado.

Uma das formas de se trabalhar a pesquisa é por meio da pesquisa-ação participativa que, como afirmam Thiollent (1986) e Pereira et al. (2018) é uma forma de pesquisa na qual o pesquisador pode estar envolvido não como observador externo, mas sim com participante dos trabalhos junto ao grupo em estudo.

O campo de estudo desta pesquisa foi a Escola Municipal Augusto de Carvalho, situada no distrito de Engenheiro Passos-Resende/RJ. É uma iniciativa do Serviço de Orientação Educacional/SOE, tendo como responsável a pedagoga Rosimar Alencar Silva Barbosa. Esta escola atende cerca de 400 alunos da Pré-escola ao $7^{\circ}$ ano do Ensino Fundamental anos finais. A pesquisa foi desenvolvida durante o terceiro e quarto bimestre do ano de 2019. O objeto da pesquisa é a implantação e o desenvolvimento de eleição de representantes de turmas, participou da pesquisa os alunos do $4^{\circ}$ e $5^{\circ}$ ano do Ensino Fundamental Séries iniciais, e os alunos do $6^{\circ}$ e $7^{\circ}$ ano dos anos finais.

\section{Resultados e Discussão}

O estudo foi dialogado com uma pesquisa de caráter exploratória e descritiva, e de natureza qualitativa e para a fundamentação teórico-metodológica do trabalho o meio utilizado foi uma Revisão Bibliográfica.

Para Denzin e Lincoln (2006) a pesquisa qualitativa refere-se na interpretação do mundo, estudar os contextos naturais para entender os fenômenos e suas representações dos significados que os indivíduos lhe conferem. Esse tipo de pesquisa traz uma abordagem interpretativa do mundo, possibilitando os pesquisadores estudarem em seus contextos naturais, visando compreender os fenômenos em termos dos significados que os indivíduos a eles conferem.

Segundo Neves (1996) que através da pesquisa qualitativa é possível verificar elementos relevantes, na percepção e compreensão do objeto pesquisado em seu contexto. Destaca-se que a pesquisa qualitativa é objetiva, com constatações estatísticas.

O primeiro passo foi uma pesquisa exploratória, onde fez-se um levantamento do histórico da Escola Municipal Augusto de Carvalho, a mesma foi criada pelo Decreto Municipal número 188/GP/92 em 28 de agosto de 1992. A clientela atendida, como também as características e aspectos culturais do Distrito de Engenheiro Passos.

O segundo passo após esse levantamento, foram várias rodas de conversas com a equipe diretiva, tendo em vista identificar as principais necessidades da escola, no contexto de formação e desenvolvimento humano nas relações interpessoais, entre pares e escola e família.

O terceiro passo seguido foi relacionado às entrevistas com os professores do Ensino Fundamental anos iniciais e finais, os mesmos elencaram as dificuldades das turmas e concordaram que um projeto de representante de turma, auxiliaria na organização da rotina escolar, promovendo o protagonismo.

Partindo desse pressuposto e nas observações in loco. Após o levantamento das necessidades descritas pela equipe pedagógica e docente, o quarto passo foi ouvir os alunos e para isso adotou-se as sessões coletivas, as rodas de conversas e as mesas de debates. Nessas reuniões debateu-se o projeto de representantes com os alunos do $4^{\circ}$ ao $7^{\circ}$ ano, e percebeu-se que faltava uma representatividade, alguém que pudesse falar por eles, todos chegaram à conclusão que a escola deveria realizar a eleição. Desta forma em julho de 2019, em consonância com os professores realizamos a primeira eleição de Representantes de Turmas. Foram eleitos dezoito alunos que passaram por uma triagem dos professores e orientação educacional, sendo os prérequisitos: ser criativo, solidário, ético, responsável, com boas notas, boa relação interpessoal com a turma e funcionários e frequente as aulas. As eleições movimentaram a escola, que pela primeira vez em sua história recebeu tal projeto. Houve um 
engajamento de toda a comunidade escolar e das famílias que foram comunicadas quanto ao projeto. A divulgação ampliou a nova maneira de conceber a escola. Embora o projeto representante de turma seja uma prática replicada em muitas escolas brasileiras, porém a novidade pensada, foi desenvolver as habilidades socioemocionais e formar novas lideranças capazes de atuar a partir de conhecimentos já construídos, atuar de forma ética e autônoma, conforme descrito nas competências gerais da BNCC, que cita a: argumentação, empatia e cooperação e autonomia.

O projeto contou com os seguintes objetivos apresentados no Quadro 1

Quadro 1 - Conteúdos e objetivos do projeto.

\begin{tabular}{|c|c|}
\hline Conteúdos Temáticos & Objetivos \\
\hline 1-Eleição dos Representantes de Turma & $\begin{array}{l}\text { Destacar e eleger alunos que possam atuar } \\
\text { com atores sociais, a fim de promover a } \\
\text { cidadania e o envolvimento da } \\
\text { comunidade escolar visando à organização } \\
\text { e a ativa participação nos processos } \\
\text { educativos. }\end{array}$ \\
\hline \multicolumn{2}{|l|}{ Formação Continuada para os Representantes Eleitos } \\
\hline $\begin{array}{l}\text { Liderança Comprometida. Temas: } \\
\text { 1- } \quad \text { O que é ser líder/quem é o representante de turma, seu } \\
\text { perfil e funções. } \\
\text { 2- } \quad \text { Cinco passos para se tornar um aluno protagonista } \\
\text { 3- } \quad \text { Empatia X Engajamento } \\
\text { 4- } \\
\text { 5- } \\
\text { 6ecnologia a favor da aprendizagem } \\
\text { 6- Conservação do Patrimônio Público }\end{array}$ & $\begin{array}{l}\text { Refletir a respeito da liderança } \\
\text { comprometida e as suas ações em } \\
\text { benefício da comunidade e escolar. }\end{array}$ \\
\hline
\end{tabular}

Fonte: Autores.

O curso de liderança comprometida aconteceu nos meses de agosto e setembro/2019. (Quadro 2):

Quadro 2 - Períodos e atividades.

\begin{tabular}{|l|}
\hline $1^{0}$ Encontro: Quem é o representante de turma? \\
\hline $2^{\text {a }}$ Encontro: Liderança Comprometida \\
\hline $3^{\text {a }}$ Encontro: Cinco passos para se tornar um aluno protagonista \\
\hline $4^{\text {a }}$ Encontro: Empatia X Engajamento \\
\hline $5^{\text {a }}$ Encontro: Tecnologia a favor da aprendizagem \\
\hline $6^{\text {a }}$ Encontro: Despertando o líder em mim \\
\hline $7^{\text {a }}$ Encontro: Conservação do Patrimônio Público \\
\hline Cerimônia de Entrega dos certificados do curso: $27 / 09 / 2019$ \\
\hline
\end{tabular}

Fonte: Autores.

Verificou-se, que através da instituição das lideranças, o ambiente tornou-se favorável para a atuação e participação dos alunos na vida da escola. Os representantes de turmas, assumiram novas posturas diante dos desafios diários, atitudes de proatividade contribuíram para a melhoria do processo ensino/aprendizagem. Através desse protagonismo, os professores sentiramse apoiados e ajudados em momentos necessários. 
A presença dos representantes nas turmas tornou-se uma referência de colaboração e articulação entre pares, entre os professores e equipe pedagógica. A princípio os alunos sentiram-se ameaçados, como se o representante fosse um delator, porém logo constataram o contrário, sendo eles um porta voz de seus anseios, reclamações e expectativas.

Por meio do protagonismo dos alunos, coletaram-se opiniões e sugestões fundamentais para ações que corroboraram com a construção de uma escola expressiva e receptiva às diferenças, onde indivíduos que saibam se posicionar e tenha condições de fazer valer as suas reinvindicações por meio do diálogo. Partindo desse pressuposto, os representantes de turma fizeram uma consulta nas turmas para saber o que os alunos desejavam para tornar a escola melhor. Após apresentaram uma lista de sugestões, a mesma foi analisada pela equipe gestora e pelo Serviço de Orientação Educacional. Um dos apelos correspondia a organização do recreio, onde havia desenhados no chão, alguns triângulos de jogar bolinha de gude. Todavia, por algum motivo desconhecido não era permitido a prática desse jogo. Em debate com a gestão da escola, conclui-se que era o momento certo para incentivar as práticas protagonistas a começar com o recreio.

\section{Organização do I Festival de Bolinha de Gude}

Os representantes de turmas em ação conjunta com os demais alunos e a orientadora educacional organizaram o primeiro festival de bolinha de gude, com objetivo de valorizar a cultura local. O Distrito de Engenheiro Passos, é um lugar pequeno, cercado por montanhas que formam uma linda paisagem, da área externa da escola, onde ocorre o recreio os alunos tem o privilégio de vislumbrar esse cenário. Com uma vida pacata, observa-se crianças e adolescente nas ruas e praças brincando e jogando bolinha de gude. Afirma Fernandes (2009), que as brincadeiras tradicionais fazem parte da cultura lúdica, sendo as mesmas transmitidas culturalmente, de geração a geração gerando valores. Compreendendo que a brincadeira tradicional faz parte do patrimônio imaterial, cabe articular as vivências locais, a partir do chão da escola, a fim de preservar o contexto sociocultural da comunidade o qual está inserida.

O jogo propicia valores importantes como: respeito, amizade, empatia, raciocínio lógico, cumprimento de regras, e honestidade. Tais habilidades são requisitos na formação cidadã e na vida em sociedade. Por meio do jogo de bolinha de gude foi possível trabalhar as intencionalidades pedagógicas em diversas disciplinas, principalmente em matemática. Pois o jogo de bolinha de gude exige estratégia e perspicácia. Embora pareça um jogo simples, mas na verdade não é. Desta forma foi convidado para ser o juiz das partidas, o funcionário Elivelton Martins, que é carismático e querido pela comunidade escolar. Ele também, nasceu e criou-se em Engenheiro Passos, e vivenciou desde a infância as jogadas de bolinha de gude. O sucesso do evento contou com o grande esforço dele, pois ajudou na organização das equipes e nas inscrições.

O Primeiro Festival de Bolinha de Gude movimentou não somente a escola, mas também a comunidade que prestou todo apoio ao evento. Foram noventa inscritos entre meninos e meninas. 
Gráfico 1 - Alunos matriculados no Ensino Fundamental I e II.

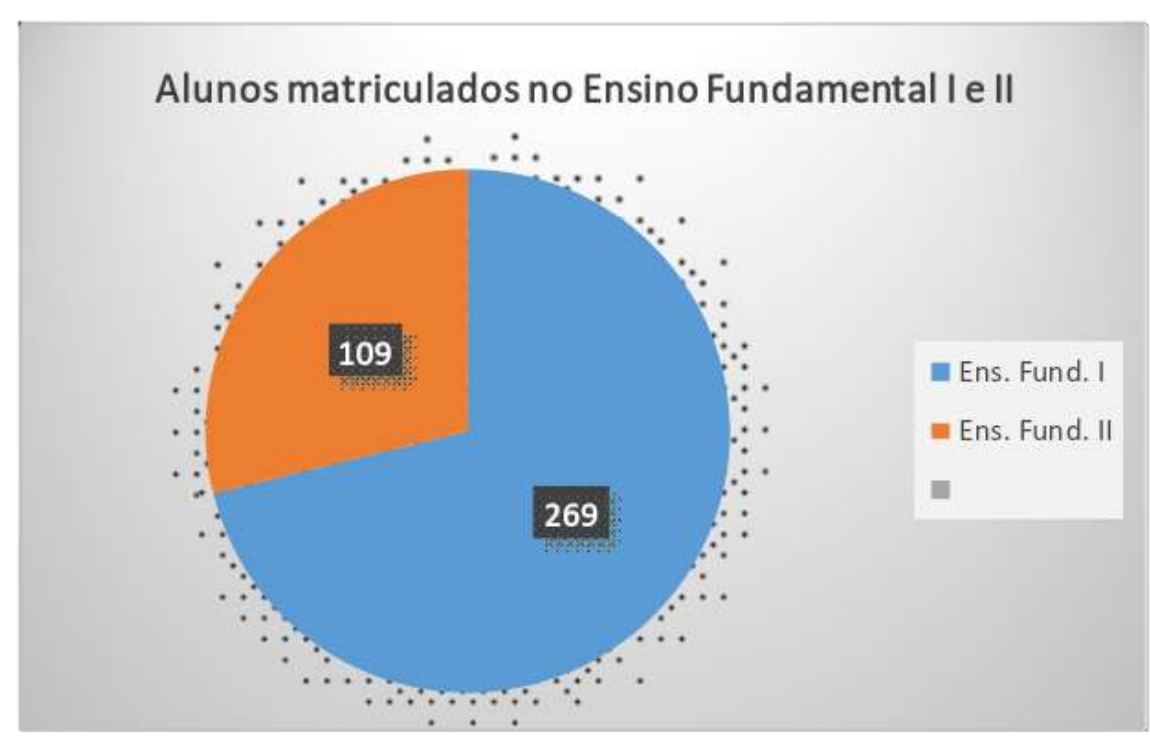

Fonte: Autores.

Verifica-se, no Gráfico 1, anterior, que a grande maioria dos estudantes era do Fundamental I.

Gráfico 2 - Alunos inscritos no festival de bolinha de gude.

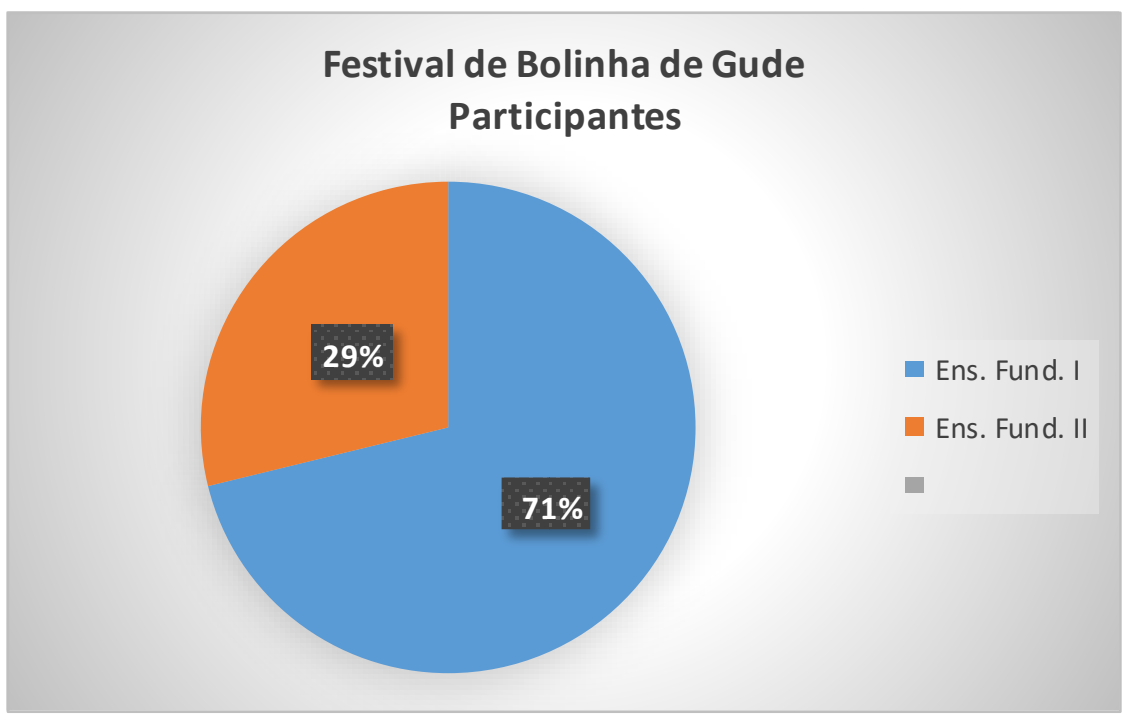

Fonte: Autores.

Observa-se que há a coerência da grande quantidade de alunos do Fundamental 1 inscritos no festival pelo fato de serem em grande quantidade e o festival ser atrativo para os pequeninos e, a Tabela 1 apresenta os finalistas dos anos iniciais do fundamental. 
Tabela 1 - Finalistas do Ensino Fundamental/anos iniciais.

\begin{tabular}{|c|c|c|c|c|}
\hline \multicolumn{5}{|c|}{ Finalistas da 3a divisão/ Ensino Fundamental anos iniciais } \\
\hline Grupos & Turmas & 10 lugar & 2o lugar & 3o lugar \\
\hline 19 grupo & 20 ano/201 & & Menina & \\
\hline 19 grupo & 3ㅇ ano / 301 & Menino & & \\
\hline 19 grupo & 3o ano/302 & & & Menino \\
\hline 29 grupo & $4^{\circ}$ ano/402 & & Menino & \\
\hline 20 grupo & 5o ano/501 & Menino & & \\
\hline
\end{tabular}

Fonte: Autores.

Já a Tabela 2 apresenta os finalistas dos anos finais do fundamental.

Tabela 2 - Finalistas do Ensino Fundamental/anos finais.

\begin{tabular}{|c|c|c|l|l|}
\hline \multicolumn{5}{|c|}{ Finalistas da 3a divisão/ Ensino Fundamental anos finais } \\
\hline Grupos & Turmas & 10 lugar & & \\
\hline 3o grupo & 60 ano/602 & & & \\
\hline 30 grupo & 70 ano/701 & & & \\
\hline \multicolumn{6}{|c|}{ Fonte: Autores. }
\end{tabular}

Nota-se que há a coerência da quantidade menor de turmas de finalistas dos anos finais do fundamental uma vez que havia menos quantidade de alunos desses anos.

\section{Formatura dos Representantes de Turma}

No dia 27/09/2019 o Serviço de Orientação Educacional/SOE organizou um evento, para homenagear os novos líderes eleitos por seus pares. Na ocasião, muitos familiares compareceram. Os certificados de conclusão do curso "Liderança Comprometida" foram entregues pelas equipes diretiva e docente aos alunos do $4^{\circ}, 5^{\circ}, 6^{\circ}$ e $7^{\circ}$ ano.

\section{Discussão}

O trabalho realizado anteriormente, percebeu-se uma lacuna no desenvolvimento das competências socioemocionais, que são habilidades para um projeto de vida na formação da cidadania. Assim identificou-se a necessidade de uma práxis que correspondesse as necessidades e problemáticas de seu tempo e território, potencializando a individualidade e formando sujeitos críticos e ao mesmo tempo com habilidades de fruir através de sentimento de pertencimento e participação e na transformação da realidade social. Nesse sentido, a implantação da eleição dos representantes de turma, seguido da formação continuada, revelou-se uma proposta capaz de despertar o protagonismo infantil e juvenil.

Protagonismo, origina-se do grego, protos é traduzida no latim por principal, primeiro e de agonistes lutador, competidor. No teatro e no cinema o termo define o personagem principal. No campo educacional o termo foi utilizado por Antônio Carlos Gomes da Costa, que destaca, o aluno como o ator principal na prática educativa e que deverá estar envolvido na vida da escola.

O protagonismo juvenil pode ser definido como:

“... é a participação do adolescente em atividade que extrapolam os âmbitos de seus interesses individuais e familiares e que podem ter como espaço a escola, os diversos âmbitos da vida comunitária; igrejas, clubes, associações e até mesmo a sociedade em sentido mais amplo, através de campanhas, movimentos e outras formas de mobilização que transcendem os limites de seu entorno sócio comunitário.” (Costa, 1996:90) 
A concepção de Protagonismo Juvenil abarca múltiplas ideias, alterando apenas a dinâmica ideológica, política e social. Vale uma análise etimológica da palavra, para entender e respaldar o presente projeto. Em Sacconi (2010, p.1685) “protagonista”, é a derivação do grego corporais e verbais são realizadas. Atualmente a palavra vem sendo usada para expressar ações brandas, onde não se trava luta. Foi substituída por ações dos atores sociais no espaço público, travada no campo social e político. Segundo os escritos de Costa (2001a):

A palavra passou a ser usada no teatro e na literatura para designar os atores principais de um enredo teatral ou as personagens principais de uma trama literária. Mais recentemente, a sociologia e a política, com base na ideia de atores sociais, passou a chamar de atores "protagônicos" ou de protagonismos os agentes principais de um movimento ou dinamismo social (Costa, 2001a, p. 11).

Segundo Adriana Friedmann, educadora e doutora em Antropologia da Infância, o protagonismo infantil é um movimento novo, que tem sido visto por diferentes segmentos da sociedade. Acontece onde há grupos que tenha crianças, de diversas faixas etárias, culturas, faixas socioeconômicas podem expressar seus pensamentos, sentimentos, vivências, opiniões, reinvindicações, preferências e realidades da vida.

A escola contemporânea sob um novo olhar, levando em consideração a diversidade e o pluralismo de sua clientela, tem a oportunidade de promover o protagonismo. Envolver os alunos, de maneira a criar uma rede de colaboração e incentivo entre pares, a fim de impactar a comunidade escolar e entorno. Para que as ações protagonistas tenham sucesso e cumpra o objetivo proposto, é essencial a intervenção do professor, pois ele é um profissional dotado de um capital social e cultural, mas é importante o envolvimento e engajamento do aluno que tem que ter o protagonismo e não a decisão somente do professor (Oliveira et al., 2020 e, Faria et al. 2020). Os alunos, como sujeitos sociais podem exercitar o protagonismo de maneira relevante, preparando-os para a vida na sociedade e do trabalho. Ao refletir sobre o sentido amplo da educação como um processo formativo que se desenvolve em diversos locais, "na convivência humana, vida familiar, trabalho, instituições de ensino e pesquisa, nos movimentos sociais e organização da sociedade civil e nas manifestações culturais” (Brasil, 1996).

Educar também é criar espaços para que o aluno possa empreender na realização de suas potencialidades no campo pessoal e social. Partindo desse pressuposto, o projeto Representantes de turma: Desenvolvendo o protagonismo infantil e juvenil, tem em sua premissa a responsabilidade de abrir espaço para uma maior atuação dos atores sociais, proporcionando a participação e organização do cotidiano escolar. Afinal, se a razão da escola são os alunos, nada mais justo que ouvir suas opiniões, ideias e desejos. Mover a força juvenil no seio escolar é dar-lhes oportunidade de iniciativa, responsabilidade e liderança. Para Konterllnik (2003) o protagonismo liga-se ao acesso a cidadania e responsabilidade democrática através da participação, onde os adolescentes se juntam e desenvolvem códigos e estilos próprios, organizam seus próprios mundos, de acordo com suas subjetividades.

Evidenciou-se através da eleição de representantes de turma, o protagonismo ampliando novos movimentos em prol da comunidade escolar, a reflexão de si e do outro, a alteridade, a preservação do meio ambiente, a preservação do patrimônio público, a empatia, o diálogo, a colaboração e a solidariedade. A compreensão do papel do representante possibilitou a articulação entre os pares. Os líderes se tornaram sensíveis e passaram a compreender os desafios do cotidiano escolar, para tanto, contribuindo com soluções. Entende-se, que o sucesso dessas ações protagonistas, foi resultado do curso de formação continuada para os novos líderes, tendo em vista que os temas elencados tiveram uma intencionalidade de desenvolver as habilidades essenciais no protagonismo infantil e juvenil. A Liderança Comprometida contemplou as competências da Base Nacional Curricular Comum/BNCC, que cita as dez competências gerais, vale destacar a competência número seis e nove, a autogestão para exercer a sua cidadania com responsabilidade nos princípios da ética e liberdade. E a empatia e cooperação.

A formação de uma liderança comprometida com a valorização da escola pública, propõe uma melhoria nos resultados e mais parceria com o corpo técnico-diretivo, docente e demais departamentos da unidade escolar. Outro fator, pretendido é a 
participação ativa de todos os alunos que é despertado através das lideranças de turma. Quando o protagonismo infantil e, juvenil entram em cena: a escola, passa a pertencer-lhes de fato e de direito, o senso de pertencimento, de cuidado e zelo começa a se tornar natural. As autoras Anavitarte, Vicent e Muñoz (2003) ressaltam a participação ligada a ação dos atores sociais em uma comunidade, em Costa (2001a; 2001b, 2002;2003) o protagonismo é uma proposta educativa que estimula a cidadania por parte dos atores sociais, acompanhada de práticas solidárias, além da preocupação e do bem comum para todos na democracia, desperta nos jovens e nos adolescentes formas críticas e criativas.

\section{Considerações Finais}

O presente projeto, alcançou os objetivos propostos e respondeu ao problema inicial da falta de expressividade, desestímulo, infrequência às aulas e descuido com o patrimônio público. Em decorrência das análises realizadas por meio da pesquisa de campo e sustentada pelo referencial teórico é relevante apontar algumas considerações, como: a eleição dos representantes de turma, foi um marco importante para incentivar os pares, a pesquisa demonstrou que houve uma mudança na maneira de encarar a eleição dos representantes de turma, ao contrário de serem considerados os delatores da turma, foram aceitos como parceiros e representantes de seus direitos, através da organização do festival de bolinha de gude, houve um engajamento coletivo e contribuição voluntária, os recreios foram reorganizados, e a bolinha de gude começou a fazer parte desse momento. A infrequência as aulas diminuíram e os alunos da zona rural voltaram a frequentar as aulas, sendo incentivados pelos representantes de cada turma. Não houve evasão, os alunos fizeram uma campanha de preservação do patrimônio público, depois dessa conscientização coletiva, as salas do Ensino Fundamental II foram reformadas e a escola ganhou novas mesas e carteiras, as quais foram preservadas. Em relação as entrevistas, é válido ressaltar que os entrevistados responderam com entusiasmo e citaram outros pontos que são relevantes para a pesquisa. A visão filosófica também mostra-se interessante, Rousseau nos faz pensar a possibilidade de uma educação que respeita a individualidade, a autonomia e a liberdade do educando, cujo objetivo é a vida boa em todos os aspectos.

Finalizando, a pesquisa evidenciou um sentimento de pertencimento dos alunos, o trabalho em equipe e a tomada de decisões em prol de do bem comum. E devido o êxito do projeto, o mesmo foi inserido no calendário escolar da escola.

\section{Agradecimentos}

Agradecemos à Secretária de Educação Municipal de Resende SME/EDUCAR, à Direção e professores(as) e demais funcionários da Escola Municipal Augusto de Carvalho, localizada no distrito de Resende/RJ, ao Serviço de Orientação Educacional/SOE e a todos alunos que participaram dos estudos e desta forma ajudaram à desenvolver a pesquisa voltada para o saber da sociedade em relação às práticas escolares em desenvolvimento.

\section{Referências}

ANAVITARTE, E. A.; VICENT, R. C.; MUÑOZ, M. M. De La participación al protagonismo infantil: propuestas para La acción. Ed. Plataforma de Organizaciones de Infancia, Madrid, 2003.

BARBOSA, P. S. C. Ensino e aprendizagem: reflexões sobre a proposta pedagógica de Jean-Jacques Rousseau. Research, Society and Development, v.9, n.8, e168985534, 2020(CC BY 4.0) | ISSN 2525-3409 | DOI: http://dx.doi.org/10.33448/rsd-v9i8.5534

BRASIL. Leis e Decretos. Constituição da República Federativa do Brasil. Brasília, 1988.

BRASIL. Leis e Decretos. Lei n. 9394 - Estabelece as Diretrizes da Educação Nacional.

CERVO, A. L.; Bervian, P. A. Metodologia Científica. 4.ed. São Paulo: Makron Boooks, 1994.

COSTA, A. C. G. Protagonismo Juvenil: adolescência, educação e participação demográfica. Salvador: Fundação Odebrecht, 2000.

CUSSIANOVICH, A.; MÁRQUEZ, A. M. Hacia una participación protagónica de niños, niñas y adolescentes. Save the Children Suecia. Lima.2002. 
DENZIN, N. K. e LINCOLN, Y. S. Introdução: a disciplina e a prática da pesquisa qualitativa. In: DENZIN, N. K. e LINCOLN, Y. S. (Orgs.). O planejamento da pesquisa qualitativa: teorias e abordagens. 2. ed. Porto Alegre: Artmed, 2006. p. 15-41.

FARIA, M. B. et al. The importance of the use of scientific experiments for Science education in Fundamental Education: A case study. Research, Society and Development, v.9, n.7, p.1-15. 2020. Disponível em: https://rsdjournal.org/index.php/rsd/article/view/4159/3469. Acesso em 20 março de 2021.

FERNANDES, T. B.; LÚCIO, G. H.; SOUSA, F. R. L. de; SILVA, F. A. M. da. Leadership studies of middle school students in a public school of brazilian basic education. Research, Society and Development, [S. 1.], v. 8, n. 4, p. e3384910, 2019. DOI: 10.33448/rsd-v8i4.910. Disponível em: https://rsdjournal.org/index.php/rsd/article/view/910. Acesso em: 23 mar. 2021.

GIL, A. C. (1999). Métodos e técnicas de pesquisa social. 5. ed. - São Paulo: Atlas. GODOY, A. S. (1995). Introdução à pesquisa qualitativa e suas possibilidades. Revista de Administração de Empresas. São Paulo. 35 (2). 57 - 63.

HÜHNE, L. M. Metodologia Científica - Caderno de textos e técnicas. 4.ed. Rio de Janeiro: Agir, 1990.

LAKATOS, E. M.; MARCONI, M. A. Fundamentos de metodologia científica. 3.ed. rev. ampl. São Paulo: Atlas, 1991.

MARTINS, A. Manual para a elaboração de projetos de pesquisa. Rio de Janeiro: Universidade Gama Filho, 1998.

MENDES, G.; TACHIZAWA, T. Como fazer uma monografia na prática. 4. ed., Rio de Janeiro: Fundação Getúlio Vargas, 1999.

MICHEL, M. Metodologia e pesquisa científica em ciências sociais - Um guia prático para acompanhamento da disciplina e elaboração de trabalhos monográficos. São Paulo: Atlas, 2005.

OLIVEIRA, M. E. P. A. et al. Science teaching in the early years of elementary school: student learning and teacher practice. Research, Society and Development. v.9, n.6, p. e163963644, 2020. DOI: 10.33448/rsd-v9i6.3644. Disponível em: https://rsdjournal.org/index.php/rsd/article/view/3644. Acesso em: 11 abr. 2021.

PEREIRA, A. S. et al. Metodologia da pesquisa cientifica. Santa Maria: UAB/NTE/UFSM, 2018.

THIOLLENT, M. Metodologia da pesquisa-ação. São Paulo: Cortez, 1986.

VERGARA, S. C. Projetos e Relatórios de Pesquisa em Administração. 3.ed. local: Atlas, 2000. 